\title{
MODERNISMO E NACIONALISMO: CASOS PARADIGMÁTICOS EM PORTUGAL E ESPANHA
}

\author{
Modernism and Nationalism: Paradigmatic cases in Portugal and Spain
}

Teresa Lousa

Doutora em Ciências da Arte e do Patrimônio (FBAUL) Universidade de Lisboa, Faculdade de Belas Artes. Investigadora Integrada do CHAM (FCSH, Universidade NOVA de Lisboa) Lisboa, Portuga teresa.lousa@gmail.com

Jhttps://orcid.org/0000-0001-6574-6901

\section{RESUMO}

O modernismo português que irrompeu nos anos 1914 e seguintes caracterizou-se por uma compleição politicamente tradicionalista, nacionalista e antiliberal. Personalidades desta geração como António Ferro e Raul Leal cedo manifestaram o seu interesse pelo fascismo e a sua descrença na República, o que naturalmente levou a que expressaram uma visão política e cultural que acabou por ver no ideário do Estado Novo a confirmação dos seus anseios nacionalistas. Mas também em Espanha Eugenio D'Ors, amigo de Salazar e de António Ferro, constitui um caso paradigmático de um intelectual que tendo colaborado com revistas modernistas como Quatre gats ou Pèl \& Ploma, mais tarde acaba por romper com o Modernismo por achar que esta estética era de uma espontaneidade estéril sem direcção.

PALAVRAS-CHAVE: Nacionalismo. Antirrepublicanismo. Modernismo. António Ferro. Raul Leal. Eugenio D’Ors.

\section{ABSTRACT}

The Portuguese modernism that erupted from 1914 on was characterized by a political traditionalist, nationalist and antiliberal complexion. Personalities of this generation, such as António Ferro and Raul Leal, soon manifested their interest in fascism and their disbelief in the Republic. This interest naturally led them to express a political and cultural vision that eventually saw the confirmation of their nationalist yearnings in the ideas of the Estado Novo. Nevertheless, also in Spain, Eugenio D'Ors, who was a friend of Salazar and Antonio Ferro, is a paradigmatic case of an intellectual. He has collaborated with modernist magazines such as Quatre gats or Pèl \& Ploma, but later, he breaks with Modernism for thinking these aesthetics were sterile and without direction.

KEYWORDS: Nationalism. Anti-republicanism. Modernism. Ideia Nacional. Raul Leal.

\section{PRIMEIRA GERAÇÃO MODERNISTA E APROXIMAÇÃO POLÍTICA À DIREITA}

A irrupção do Modernismo situa-se numa época de crescente instabilidade, de recessão económica, de alteração de gostos, de hábitos, de modas, de estéticas; de rutura com anteriores ícones; de plasmação de novas fórmulas literárias e artísticas. Se essa rutura se efetiva, é ainda com base no compromisso com uma estética finissecular levada às últimas consequências: o impressionismo e o pós-simbolismo são as fontes do desbravamento de expressões cada vez mais ousadas, mais arrojadas, celebrizando o insólito, o "berrante", a agressividade como atitude por oposição a outras éticas. De realçar 
que esta viragem se situa no período da Primeira Guerra Mundial, adquirindo uma personalização e um caracter próprios no pós-guerra: o Dadaísmo, o Surrealismo, etc.

O Modernismo caracteriza-se sobretudo pelo rompimento com o passado. Nesta nova afirmação de mudança radical o caso português apresenta certa especificidade: podem confundir-se uma certa anarquia e a sua força demolidora e rebelde com o nacionalismo que criticaria a situação atual do país, com contornos de direita.

Em Portugal, a rutura com a herança oitocentista foi um processo lento que decorreu nas primeiras décadas do século XX. A Exposição dos Livres no Salão Bobone em 1911, onde expuseram Manuel Bentes (1885-1961), Eduardo Viana (1881-1967), Emmerico Nunes (1888-1968), Alberto Cardoso (1881-1942), Francisco Smith (1881-1961), Domingos Rebelo (1891-1975) e Francisco Álvares Cabral (1887-1947), é considerada a primeira manifestação, ainda que tímida, desse desejo de modernização.

Na pintura especificamente podemos falar de uma $1^{a}$ Geração apelidada Geração de Paris, que de certa maneira coincide cronologicamente com a Revista Orpheu, revista "cujo nome passa a identificar uma geração e uma poética" (MARTINS, 1994, s.p.). Apesar de só ter tido dois números a revista constitui o epicentro do início de um estilo próprio dentro dos movimentos vanguardistas (o que se manifesta na expressão usada "à maneira de Orpheu"), numa sociedade passadista onde provoca escândalo com a sua novidade e activismo.

O que esta nova Geração trazia era uma nova estética internacional apreendida sobretudo em Paris, onde estiveram. Presente nas duas gerações modernistas esteve Almada Negreiros, sempre apelidado de futurista, um dos artistas preferidos do Estado Novo, autor de múltiplas obras públicas ao longo da sua vigência, nomeadamente a realização dos vitrais e da decoração mural do baptistério e da capela-mor da modernista Igreja de Nossa Senhora de Fátima em Lisboa.

É por vezes olhada com pudor a relação promíscua entre modernismo artístico e literário e o pensamento de direita de pendor nacionalista, como se esta relação diminuísse em alguma coisa os seus intervenientes e a sua obra:

É minha convicção que, em Portugal, alguns dos melhores artistas e escritores das décadas de 1910 e 1920, em particular aqueles associados com o modernismo (Orfeu, 1915) e o futurismo (Portugal Futurista, 1917), contribuíram de forma significativa para a "atitude de espírito" e a "política estética", que deram ao fascismo a sua aura inicial e que atraíram criadores e intelectuais. O fato de as tendências culturais e políticas terem vindo a divergir, e de os regimes autoritários e totalitários da década de 1930 terem, de modo crescente, dado lugar ao tradicionalismo cultural, é outro aspecto 
que confirma a semelhança de padrões entre Portugal e o resto da Europa. (CABRAL, 2014, p. 95)

Na opinião de Cecília Barreira, se não podemos associar a Revista Orpheu a uma direita, havia outras revistas que cruzavam estéticas de compromisso, e aí entra $A$ ldeia Nacional (1915-1916). Homem Cristo Filho, o seu director, que seria designado, mais tarde, como o primeiro fascista português, também tinha ligações muito fortes ao Modernismo. 0 secretário-geral da revista $A$ Ideia Nacional era Victor Falcão, o qual chegaria a ser crítico de arte da revista Contemporânea e crítico literário do Diário de Lisboa. Este e José Pacheco são os rostos da modernidade na segunda fase da revista em 1916. Este último ter-se-á identificado com o poeta e escritor Sá-Carneiro, elaborando a capa da obra Dispersão e de Céu em Fogo. Mas não só: foi ele quem desenhou a primeira capa do Orpheu. "Quando foi para Paris em 1910, conviveu aí com os pintores Amadeo de SouzaCardoso e Jorge Barradas, o poeta Mário de Sá-Carneiro e, presumivelmente, o jornalista Homem Cristo Filho." (BARREIRA, 2015, p. 140)

Esta revista ostensivamente monárquica e conservadora espanta-nos ao conciliar uma estética arrojada com um quadro tradicionalista. Essa aproximação de conservadores e modernos deve ser entendida à luz de uma desilusão em relação à República portuguesa.

A fugaz aproximação entre integralistas, monárquicos e modernistas nas páginas de A Ideia Nacional leva-nos, entretanto, a outra ordem de considerações: quer o integralismo, quer o modernismo eram 'aristocratas', pugnavam por ideais cujos contornos coincidiam no geral. Um especto os separava, no entanto: o visionamento passadista inerente à visão do mundo integralista; os preconceitos morais e intelectuais; as reações face ao novo e ao diferente. O ódio ao 'burguês', aos valores da sociedade liberal, era o traço de união. (BARREIRA, 2015, 141)

Os ideais do Republicanismo não mobilizam os artistas. A estética do modernismo não se compadece com a da República que lhes parece oitocentista. Quase todos os representantes do modernismo rejeitam cultural e ideologicamente o novo regime republicano, que de novo não Ihes parece ter nada, ao contrário, transmite-Ihes a energia passadista que eles querem ultrapassar.

\section{ANTÓNIO FERRO: DA DIRECÇÃO DA REVISTA ORPHEU À PRESIDÊNCIA DO SNI}

António Ferro nasceu em 1895 e conhece Sá-Carneiro no liceu. Desde jovem é fascinado pelas artes e sensível a esta, aderindo ao modernismo, anti-saudosista, europeizante. Com Sá-Carneiro, Santa-Rita Pintor, Pessoa e Almada abraçam o projecto 
do Orpheu. Ferro será editor da revista, que sairá em 1915, e terá dois números e que é talvez o acontecimento literário mais importante deste período. António Ferro surge como seu editor oficial. Segundo relata o seu filho António Quadros terá sido o seu amigo Mário de Sá Carneiro que o convidou precisamente por este ser ainda menor de idade. Contudo este insipiente envolvimento não chega para fazer deste um interveniente desta primeira geração do modernismo português. Na opinião de Barreto:

[...] a sua ligação ao grupo do Orpheu teve um cunho superficial, aliás bem tipificado por Fernando Pessoa, ainda que indirectamente, num texto dos anos 1920 em que contava brevemente a história da revista. Depois de apontar certas confusões que habitualmente se faziam quando se falava dos "poetas do Orpheu", Pessoa, sem individualizar ninguém, referia-se àqueles que estiveram ligados [à revista], ainda que como simples espectadores próximos ou amigos, e sem que nela influíssem ou colaborassem (Castex, 1968). Todos os testemunhos e documentos conhecidos, relativos ao grupo e à revista, confirmam plenamente que Ferro foi apenas um daqueles espectadores próximos ou amigos, sem qualquer contributo palpável para a revista nem qualquer influência nela. (2015, p. 216-223)

Se não devemos associar António Ferro ao fulgor do Modernismo português, podemos seguramente associá-lo à vaga fascista que varria a Europa, que culminaria alguns anos mais tarde com o longo domínio do Estado Novo. Nos anos 20 destacou-se no jornalismo e cosmopolitismo: no Brasil participa da Semana de 22 em São Paulo. Ferro participa do movimento modernista brasileiro junto de Sérgio Milliet, Oswald de Andrade, Mário de Andrade e Manuel Bandeira, fazendo conferências em várias cidades e escrevendo artigos para a revista "Klaxon" revista modernista da época.

Mas é o seu entusiasmo pelo fascismo que ficará bem patente nas suas entrevistas Viagem à Volta das Ditaduras (1927). Aqui entrevistou Mussolini e chegou mesmo a ter uma entrevista marcada com Hitler (mas que não se chegou a concretizar). Para o Estado Novo, António Ferro ${ }^{1}$ foi eleito o director do Secretariado da Propaganda Nacional (SPN). A cumplicidade entre este e Salazar era tal que foi o próprio Ferro quem sugeriu a Salazar em 1932 a criação deste organismo que se dedicasse à propaganda e à formulação doutrinária, à qual dará o nome de Política do Espírito. Mais tarde o mesmo organismo muda de nome para Secretariado Nacional de Informação (SNI) e Ferro mantém-se seu director até 1949.

1 Ver Figura 1 
Nas palavras de Artur Portela (1987, p. 12) é Ferro que antevê a utilidade de uma mobilização da arte para a construção da grande fachada da nacionalidade, da nacionalidade que Salazar se propunha devolver à nação.

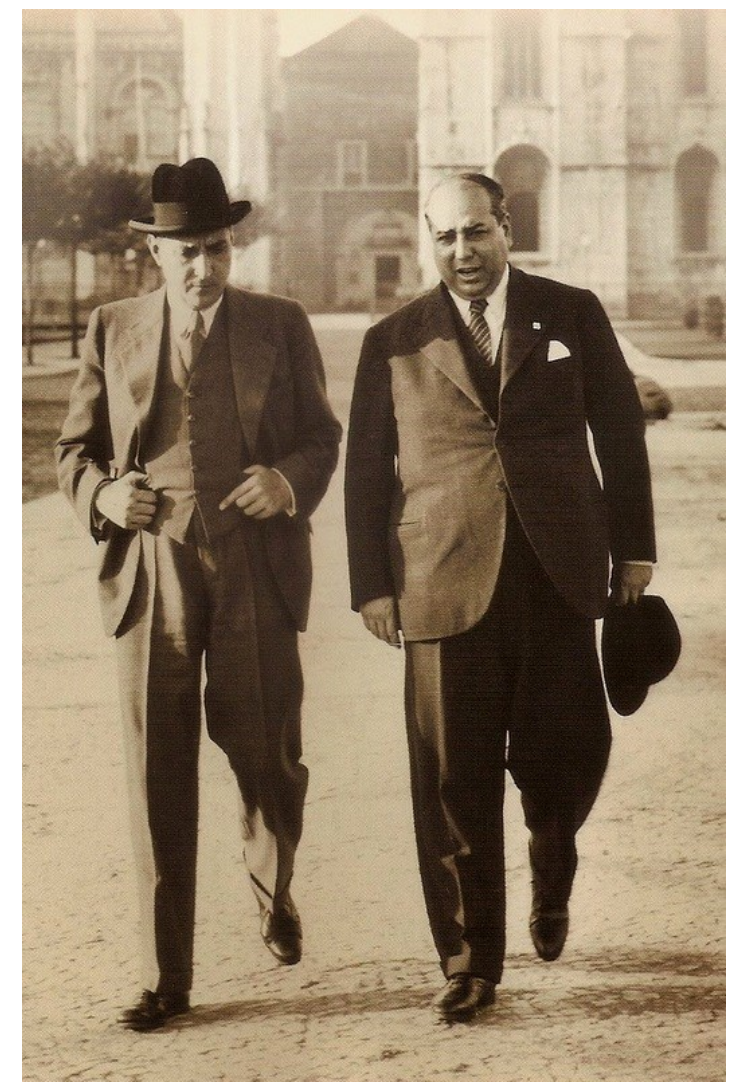

Figura 1- Oliveira Salazar e António Ferro: Foto que dá Capa ao livro "António Ferro: O Inventor do Salazarismo" de Orlando Raimundo, Lisboa: Dom Quixote, 2015.

Assim António Ferro ficará sempre relativamente incompreendido: nem foi um seguidor das ideias contestatárias do breve fenómeno do «Orpheu», nem pode ser verdadeiramente o braço direito cultural e artístico de Salazar, pois este representava a expressão da grande burguesia agrária das classes médias que culturalmente se situavam num conservadorismo rural bem português, e a «política do espírito» de António Ferro continha um discurso estético de carácter vanguardista e cosmopolita.

A acção cultural e estética de Ferro que teve em «Orpheu» na sua génese é uma criação de Ferro, apenas possível graças à herança futurista e à sua capacidade de articular várias expressões culturais modernistas, em particular a sua sensibilidade ao fenómeno marinettiano do Futuro-fascismo. A «política do espírito» é uma política global, de propaganda, de pendor sócio-cultural que integra todas as artes como instrumentos totalizantes, "do cinema, oteatro, o cartaz, as artes gráficas, a publicidade, o turismo, a 
invenção do rosto cultural moderno do regime, a mobilização de consideráveis sectores culturais artísticos portugueses". (Portela, 1987, p. 53)

Nas palavras poéticas de António Quadros, filho de António Ferro, o seu pai terá sido de todos os representantes da primeira geração modernista "o apóstolo, o missionário, o homem que levou a verdade ao povo, que a espalhou, a transmitiu, a pregou através do País e do estrangeiro" (1963, p. 9) através da difícil tarefa de intervir política e efectivamente na vida e nos destinos de uma nação.

\section{RAUL LEAL: UM CASO PARADIGMÁTICO DO MODERNISMO NACIONALISTA}

Raul Leal ${ }^{2}$ que com o apoio de Fernando Pessoa, participa do movimento modernofuturista de Orpheu e no Portugal Futurista (1917) foi um espírito incompreendido. Como colaborador do Orpheu, foi nas palavras de Jorge de Sena um dos seus mais significativos representantes da integral aventura espiritual a que muitos participantes de tais movimentos se não atreveram nunca. ${ }^{3}$ Acerca de Raul Leal afirmará também Mário Cesariny num poema ímpar: "Raul Leal era o único verdadeiro doido do «Orpheu». Ninguém Ihe invejasse aquela luxúria de fera? Invejava-a eu." ${ }^{4}$

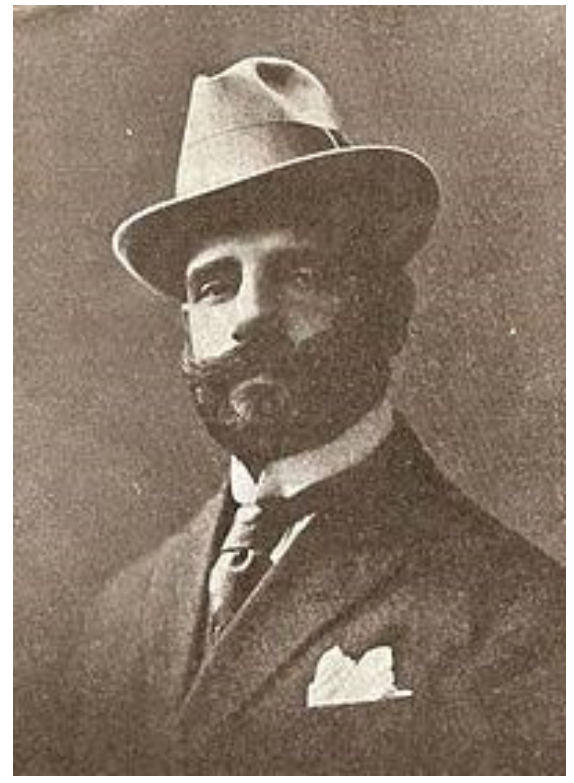

Figura 2 - Raul Leal.

\footnotetext{
2 Ver Figura 2

${ }^{3}$ Disponível em: https://www.apagina.pt/?aba $=7 \&$ cat $=91 \&$ doc $=8047 \&$ mid $=2$

4 Disponível em: https://www.escritas.org/pt/t/2839/o-raul-leal-era
} 
Já em 1910 numa conferência, que lançaria o escândalo, intitulada: $A$ Situação do Estudante em Portugal, toca temas de análise rácica e nacionalista ultrapassando em muito o positivismo naturalista que dominava a época.

Sobre a sua personalidade, o seu contemporâneo Mario Sáa afirmará que este constitui um dos primeiros futuristas portugueses, sem vestígio de farisaísmo: "Ele não é futurista, pois que é o próprio futurismo! [...] A sua metafísica é a confusão labiríntica dos sentidos, transcendência das paixões, o delírio da carne e da alma [...]." (1925, p.282)

Em 1915, edita e distribui o manifesto O Bando Sinistro onde já manifesta uma ideologia fortemente anti-republicana. Numa espécie de performance futurista e em jeito de provocação distribui os panfletos pelos cafés de Lisboa.

Politicamente Raul Leal afirma-se como monárquico convicto. Ele que foi nascido numa família nobre por parte da mãe, repudiará a República à qual lança na sua obra uma severa crítica, como aliás a generalidade dos modernistas. Leal defendia como sistema político ideal a Monarquia da Graça, "instituição que regerá os destinos das nações dentro do Super-Estado, ou Estado em que todos os indivíduos participam do Governo através da representação mais lata permitida pelo sindicalismo personalista" (GOMES, 2000: 209).

O Regime do Estado Novo e a figura sinistra de Salazar acabou por ter em Raul Leal um forte apoiante que vê neste uma figura messiânica, um "salvador de Portugal" e que já perto do fim da sua vida, como assinala Almeida, se dirige a este com um vigoroso e exacerbado "Salvé Salazar!" numa reverência própria do totalitarismo que lembra saudações como "Heil Hitler":

Os méritos salazaristas na contenção da dívida pública e na resolução do
caos financeiro que o país atravessava abririam portas a quase meio século
de ditadura, com uma larga base de apoiantes nos quais se incluíam Raul
Leal e até o próprio Fernando Pessoa, embora no caso deste de modo
passageiro. (ALMEIDA, 2018, p. 76)

A figura pouco compreendida de Raul Leal, partindo da primeira geração modernista é talvez a máxima personificação do pensamento nacionalista de carácter profundamente messiânico e esotérico que irá talvez na Geração de 1957 atingir contornos mais sistemáticos com o contributo para uma Filosofia Portuguesa de nomes como José Marinho, António Quadros.

Podemos imaginar que é apenas nos anos 80 do século $X X$ que as aspirações de Raul Leal encontrariam paralelo no mundo das artes visuais. Os "Mitolusismos" de Lima de 
Freitas ${ }^{5}$ através do seu imaginário associado aos mitos lusitanos criam o perfeito roteiro visual para a expectativa de um renascimento nacional. Não é por acaso que o filósofo Gilbert Durand (1997) vê nesta fase da pintura de Freitas o exemplo do rissorgimento popular e aristocrático que pode salvar a modernidade desesperada e desorientada. $\mathrm{O}$ filósofo que era grande amigo de Lima de Freitas vê na sua obra artística a continuidade de uma linhagem estética, ética e poética que ascende a Camões, passa por figuras como Pessoa e Raul Leal e encontra em Lima de Freitas o testemunho mais exuberante e magistral.

O seu nacionalismo atingiu extremos nunca vistos em artigos como "Portugal perante muçulmanos, hindus e pretos" (LEAL, 1962). Nesta obra Leal defende a superioridade dos Portugueses e a mediocridade dos povos colonizados. Como um profeta defendeu para Portugal uma "missão fundamental: a de criar civilização para benefício dos povos bárbaros, proporcionando-lhes o ensejo de atingir um patamar mais alto na existência, a comunhão com o Espírito." (ALMEIDA, 2018, p. 82)

\section{EUGÉNIO D’ORS E A POLìTICA CULTURAL NACIONALISTA EM ESPANHA}

Crítico de arte, ilustrador e pensador e escritor, Eugenio d'Ors ${ }^{6}$ apresenta-se como um representante ímpar do movimento regeracionista catalão: Noucentisme, linha que aproximou no início do século XX a estética à política.

Em 1920 mudou-se para Madrid, passou a escrever em castelhano e não em catalão o que não afectou o seu ideário filosófico nacionalista e pode acrescentar-Ihe uma maior visibilidade internacional. Tal mudança não foi sentida sem grandes controvérsias. Ainda hoje este intelectual é uma figura incómoda da história espanhola, para uns traiu a Catalunha e para outros não passa de um franquista ${ }^{7}$. Nesta fase escreveu alguns dos seus livros mais famosos: Tres horas en el Museo del Prado (1922), el drama Guillermo Tell (1926), La vida de Goya (1928).

\footnotetext{
5 Título do livro Gilbert Durand sobre a obra mito-lusitana de Lima de Freitas editado em 1987.

6 Ver Figura 3.

7 Apoiante e representante do regime de Franco.
} 


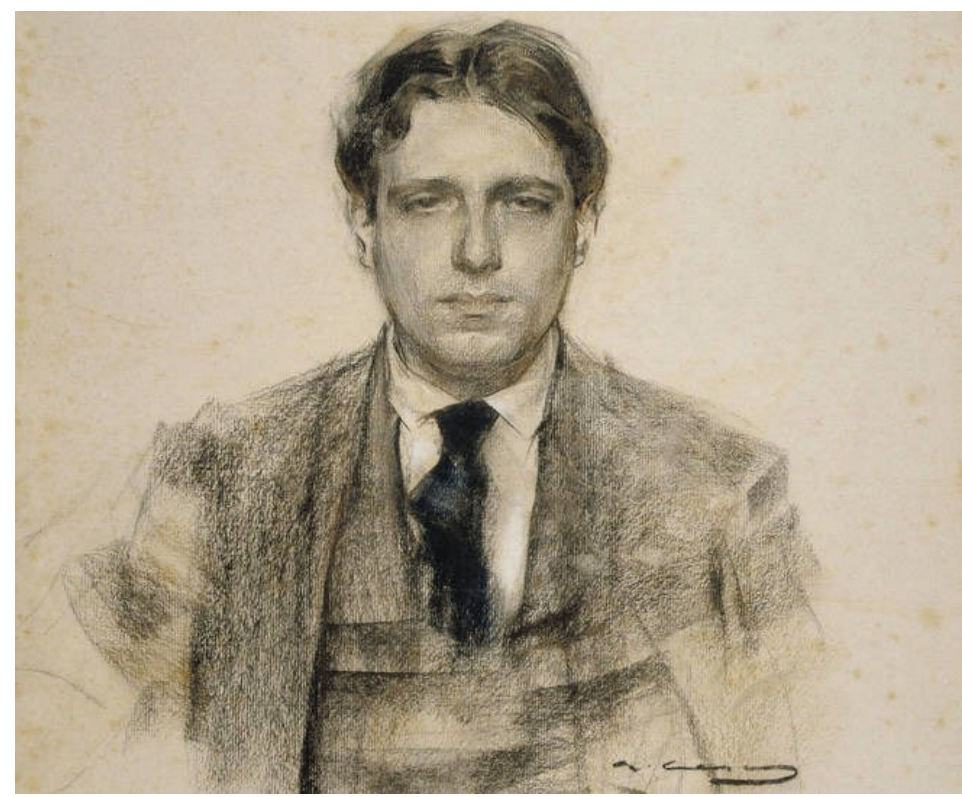

Fig. 3 - Retrato de Eugenio d'Ors por Ramón Casas.

Em 1927 foi eleito membro da Real Academia Espanhola. Pouco depois volta a Paris, onde permanece por causa da guerra civil espanhola até 1937. Aqui escreve: Paul Cézanne (1930), Pablo Picasso (1930) y Du Baroque (1935).

Nunca apoiou os ideais da República e por isso ao contrário de outros da sua geração como Ortega y Gasset foi um defensor da Monarquia e do conservadorismo. Daí se entende que se tenha convertido num forte apoiante do Franquismo ${ }^{8}$, ocupando diversos lugares institucionais ligados à cultura, tendo na década de 40 contribuído para a difusão cultural de Espanha numa óptica europeia e internacional. Foi um defensor do nacionalismo espanhol a par da tradição catalã que nunca esqueceu. Tal como António Ferro, de quem era amigo, foi um defensor e protector do regionalismo e do folclore. Escreveu o prólogo do livro de Ferro "Salazar- O homem e a sua obra" e fez a tradução espanhola do mesmo: "biografia que António Ferro dedicou a Salazar." E antes disso, conforme lembra Saez Delgado,

(...) as suas ideias devem ter alcançado Portugal em alguma das suas viagens, pois Pessoa refere o seu nome num dos escassos textos ${ }^{9}$ em que são citados escritores espanhóis: $E$, assim, não há em Espanha hoje uma figura de real destaque genial: o mais que há é figuras de grande talento -

\footnotetext{
${ }^{8}$ Regime ditatorial espanhol, liderado pelo General Franco entre 1939- 1975-77. Regime de extrema-direita baseado numa ideologia militarista, católica e nacionalista. Segundo Artur Portela "O franquismo é divisível em três grandes períodos: o período da guerra (1936-1939), o período que vai desde o final da guerra até ao auxílio norte-americano (1939-1951), e o período de decomposição (1951- desaparecimento de Franco)." (1987, p. 40)

9 Fernando Pessoa, Páginas sobre literatura e estética (ed. António Quadros), Lisboa,. Europa-América, 1986, pp. 131-132.
} 
um Diego Ruiz, um Eugenio d'Ors, um Miguel de Unamuno, um Azorín (...). (https://modernismo.pt/index.php/e/562-eugenio-d-ors)

O fascismo espanhol tem características muito específicas, quer na sua raiz sociológica e na sua personalidade ideológica, quer na estética que suscitou. A pintura franquista, de caracter regionalista como no caso de D'Ors, "pode ser representada por pintores como Sáenz de Tejada ou pelo próprio Zuloaga, que fará um retrato emblemático de Franco, de camisa azul e boina vermelha, empunhando uma bandeira." (Portela, 1987, p. 41) Este pintor, um preferido do sistema, manteve a sua carreira em alta por mais de três décadas, expondo internacionalmente ao mesmo tempo fazia uma activa propaganda franquista. "El caso de Zuloaga ha sido un escandaloso tabú en la historia del arte español. Hasta ahora nadie se había atrevido a pisar ese callo, aportando pruebas y mostrando las consecuencias que tuvo su activismo franquista." (RIAÑO, 2019)

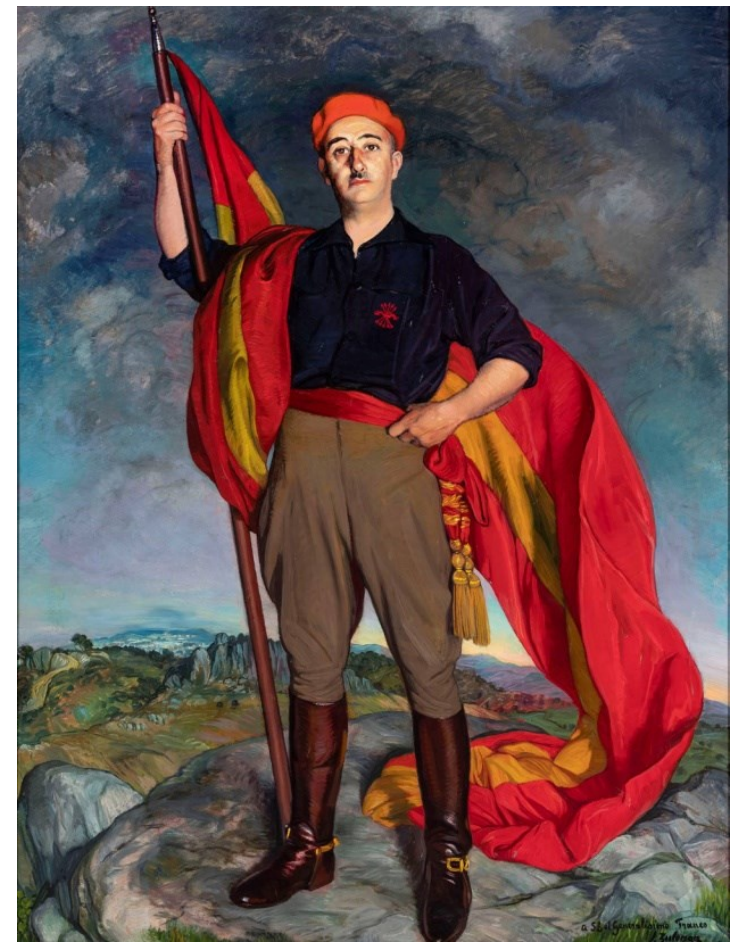

Figura 4- Retrato de Franco, por Ignacio Zuloaga (1940) Museo de Bellas Artes de Bilbao

Nos seus escritos de crítica de arte, D'Ors começou a desenvolver e a aderir a uma ideia de regeneração artística para Catalunha, e assim vai aprofundando ideais estéticos que viam o seu ideal na arte clássica da Grécia e Roma antigas, acabando por romper definitivamente com o Modernismo por achar que esta estética promovia um individualismo, um sentimentalismo e uma espontaneidade estéril sem direcção, apesar de anos atrás ter 
colaborado com as revistas literárias modernistas mais emblemáticas da época como Quatre gats, La Creu del Montseny, Pèl \& Ploma ou Auba.

A sua proposta estética chama-se noucentisme. Esta nova estética artística foi baseada em três princípios: ordem, clareza e racionalidade. Para d'Ors, o modernismo era romântico, irracional e carregado de emoção. D'Ors não fez mais do que colocar em evidência o antigo dilema da modernidade ou do classicismo, ou o que é o mesmo, as normas apolíneas - proporção e serenidade clássica - contra os excessos dionisíacos dos modernistas.

O episódio entre Eugénio d'Ors e Pablo Picasso é também um bom testemunho da personalidade contraditória e egocêntrica de D'Ors, mas também da sua rejeição ao Modernismo. D'Ors escreve dois livros sobre a obra de Picasso ${ }^{10}$, com um tom apaixonado e de censura implícito de algumas de suas páginas ${ }^{11}$ onde reuniu diversos textos. Se no início enfatiza o quanto havia do classicismo, do italianismo, do intelectualismo e do antiimpressionismo na pintura de Picasso e de como este era um exemplar noucentista de pintor, em 1946, escreverá um artigo intitulado "Adiós Pablo Picasso!", onde expressa a decepção pelo que Picasso não tem e pelo trabalho "mal feito" que foi desenvolvendo. Vale a pena lembrar que Picasso foi um dos mais emblemáticos detratores de Franco, assim como muitos outros artistas que usaram a sua arte e a sua visibilidade internacional para denunciar o regime, aspecto que certamente incidiu na anterior admiração de d'Ors por Picasso.

11 Obra reedita recentemente: Eugenio d'ors: Pablo Picasso en tres revisiones. El Acantilado, 2002. 


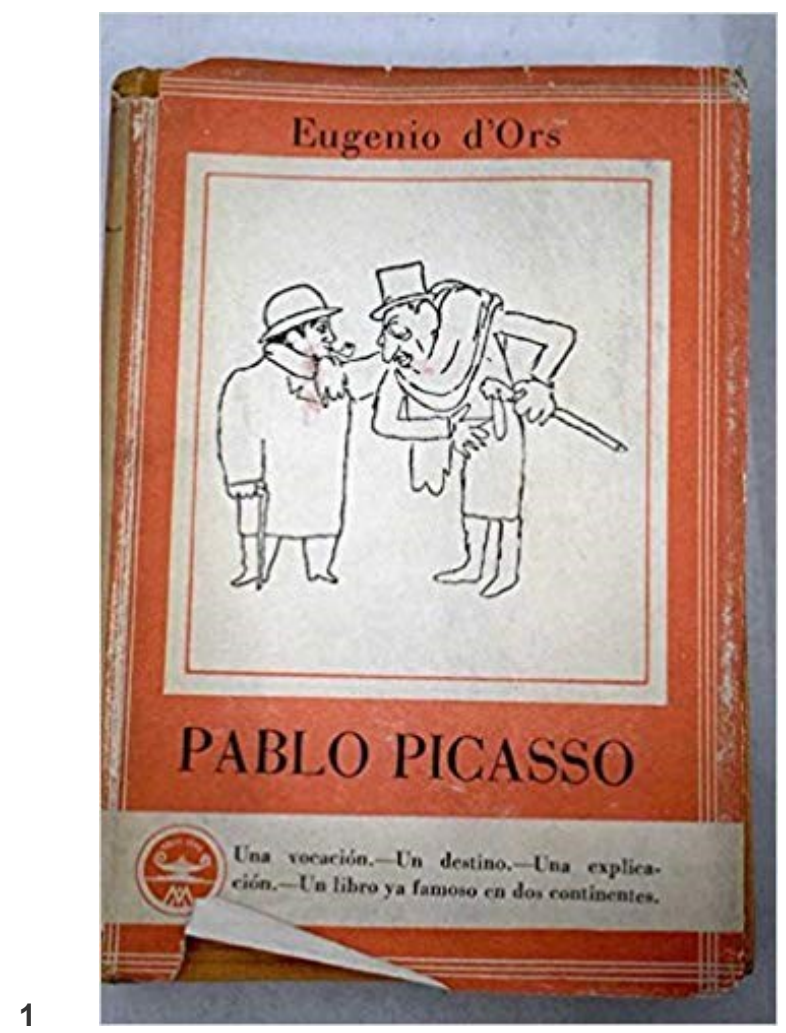

2 Figura 4- Livro de Eugénio D’Ors- Pablo Picasso en tres revisiones, Madrid, 1946.

Daria o nome de Arbitraria a uma nova estética e de Imperialista a uma nova política. Nas suas Glosas de 1906 sintetiza o seu projecto da seguinte maneira "Los noucentistes han formulado, en la idealidad catalana, dos nombres nuevos: Imperialismo-Arbitrarismo. Estas dos palabras se concentran en una única palabra: Civilidad."12

A respeito de Eugenio d'Ors algumas ideias muito negativas se foram consolidando em Espanha e manchando a sua imagem: de traidor a fascista, era Ihe também atribuído um péssimo caráter e uma excessiva vaidade. O seu ego desmedido permitiu que o próprio se comparasse com Goethe, Napoleão, Sócrates e Prometeu aquele que traz o fogo aos humanos.

D'Ors era um homem de contradições: foi catalanismo mas também franquista, correspondendo estes dois adjectivos à sua fase catalã e à sua fase madrilena. Algumas vezes tentou implementar as suas ideias estéticas e o seu projeto cultural sem se integrar completamente em qualquer projeto político, mas tal intenção não era possível nesses tempos.

D'ors é um homem que participou de comícios anarquistas liderados por Salvador Seguí, o Noi del Sucre e afirmava que o seu anarquismo era literário e sentimental. Tanto

12 https://www.ensayistas.org/filosofos/spain/Ors/introd.htm 
era amigo de Andreu Nin, o mais radical marxista de Espanha, como era próximo de Mussolini e de Oliveira Salazar.

\section{CONCLUSÃO}

Em suma, e olhando para um futuro para além de 1915-16, poderíamos analisar as contradições e o lado híbrido dos modernistas lusos e de grande parte dos monárquicos face ao fenómeno do salazarismo. Tal tendência, por vezes escamoteada por vicissitudes históricas contemporâneas, está presente em personalidades marcantes da primeira e segunda geração modernista como António Ferro, Almada Negreiros ou Raul Leal e parte sobretudo de uma rejeição do republicanismo e de uma inicial expectativa em relação ao fascismo como fenómeno europeu e a uma apetência cultural, literária, filosófica e artística votada ao nacionalismo. Paralelamente a situação em Espanha apresenta vicissitudes culturais e políticas semelhantes, de onde destacámos a figura contraditória de Eugénio D'Ors.

\section{REFERÊNCIAS}

ALMEIDA, António «Salvé Salazar!» uma carta de Raul Leal (Henoch) ao fundador do Estado Novo português. Pessoa Plural. ISSN: 2212-4179 nº 13 (P./ Spring 2018) p. 7386

AA. VV. Antologia do Futurismo Italiano. Lisboa: Editorial Veja, 1979.

AA.VV. Dicionário de Fernando Pessoa e do Modernismo Português. Coord. Fernando Cabral Martins. Lisboa: Caminho, 2008.

AA.VV. O Ano de Orpheu, Coord. Steffen Dix, Lisboa, Tinta-da-china, 2015

BARREIRA, Cecília. Nacionalismo e Modernismo - De Homem Cristo Filho a Almada Negreiros. Lisboa: Assírio \& Alvim, 1981.

BARREIRA, Cecília. " A Ideia Nacional. Algumas Confidências Modernistas e Nacionalistas" in Steffen Dix (Org.) 1915: o ano de Orpheu,pp.137-146. Lisboa: Tinta-dachina. 2015.

BARRETO, J.. António Ferro. O "editor irresponsável". In Steffen Dix (Org.) 1915: o ano do Orpheu, pp. 215-224. Lisboa: Tinta-da-china, 2015.

CABRAL, Manuel Villaverde. A estética do nacionalismo: modernismo literário e autoritarismo político em Portugal no início do século XX, Novos estudos - CEBRAP 
n98. São Paulo Mar. 2014, Disponível em

http://www.scielo.br/scielo.php?script=sci_arttext\&pid=S0101-

33002014000100006\&lng=pt\&tlng=pt Acesso em 20 dez. 2018

http://dx.doi.org/10.1590/S0101-33002014000100006

CESARINY, Mário. O Raul era. Disponível em https://www.escritas.org/pt/t/2839/o-raulleal-era Acesso em 03 dez 2018.

DELGADO, Antonio Sáez. Dicionário de Fernando Pessoa e do Modernismo Português, coordenado por Fernando Cabral Martins, Lisboa, Caminho, 2008.:

https://modernismo.pt/index.php/e/562-eugenio-d-ors Acesso em: 16 Mai 2019

DURAND, Gilbert. Mitolusismos de Lima de Freitas, Guimarães. Co-edição de

Perspectivas \& Realidades, Lisboa Galeria Gilde, 1987

FERREIRA, Paulo. Correspondence de quatre artistes portugais. Paris: PUF, 1972.

FERREIRA, José Mendes (org.) Antologia do Futurismo Italiano: Manifestos e

Poemas. Lisboa: Editorial Veja,1979.

LEAL, Raul. “O Bando Sinistro”, in Os Caminhos de Orpheu, Lisboa, Biblioteca Nacional de Portugal / Babel, 2015.

LEAL, Raul. "Portugal perante muçulmanos, hindus e pretos", in A Cooperação Revista Mensal de Cultura, Informação e Divulgação das Actividades Económicas

Nacionais, dir. José da Silva Baptista, Ano VI, n. ${ }^{\circ}$ 76, Lisboa, pp. 24 e 40, Agosto, 1962

MARTINS, Fernando Leal, "Orpheu continua", Orpheu, ed. fac-similada, $2^{a}$ ed. Lisboa: Contexto, 1994

PORTELA, Artur. Salazarismo e as Artes Plásticas, Amadora. Biblioteca Breve, 1987

QUADROS, António, António Ferro, Ed. Panorama, SNI, Lisboa, 1963

3 RIAÑO, Peio H., "El tabú de la alianza de Zuloaga y Franco, al descubierto" in El País. 18 de Outubro de 2019, https://elpais.com/elpais/2019/10/17/ideas/1571326768 359282.html

RIO, Pilar del. Enrique Moradiellos, Carme Molinero, Manuel Loff. O Franquismo, VisãoHistória, n 51. Lisboa. Edições Avulso. Fevereiro de 2019

SÁA, Mário. A Invasão dos Judeus. Lisboa: Libânio da Silva, 1925.

SERAFIM, Ferreira. Raul Leal - Um Poeta do Orpheu, disponível em https://www.apagina.pt/?aba=7\&cat=91\&doc=8047\&mid=2 Acesso em 03 dez. 2018. 


\section{Notas}

\section{AGRADECIMENTOS}

Não se aplica.

\section{CONTRIBUIÇÃO DE AUTORIA}

Não se aplica.

Concepção e elaboração do manuscrito: M. T. V. Lousa Mikosz

Coleta de dados: M. T. V. Lousa Mikosz

Análise de dados: M. T. V. Lousa Mikosz

Discussão dos resultados: M. T. V. Lousa Mikosz

Revisão e aprovação: M. T. V. Lousa Mikosz

\section{CONJUNTO DE DADOS DE PESQUISA}

Todo o conjunto de dados que dá suporte aos resultados deste estudo foi publicado no próprio artigo.

\section{FINANCIAMENTO}

Não se aplica.

\section{CONSENTIMENTO DE USO DE IMAGEM}

Não se aplica.

\section{APROVAÇÃO DE COMITÊ DE ÉTICA EM PESQUISA \\ Não se aplica.}

\section{CONFLITO DE INTERESSES}

Não se aplica.

\section{LICENÇA DE USO}

Os autores cedem à Revista Internacional Interdisciplinar INTERthesis os direitos exclusivos de primeira publicação, com o trabalho simultaneamente licenciado sob a Licença Creative Commons Attribution (CC BY) 4.0 International. Estra licença permite que terceiros remixem, adaptem e criem a partir do trabalho publicado, atribuindo o devido crédito de autoria e publicação inicial neste periódico. Os autores têm autorização para assumir contratos adicionais separadamente, para distribuição não exclusiva da versão do trabalho publicada neste periódico (ex.: publicar em repositório institucional, em site pessoal, publicar uma tradução, ou como capítulo de livro), com reconhecimento de autoria e publicação inicial neste periódico.

\section{PUBLISHER}

Universidade Federal de Santa Catarina. Programa de Pós-graduação Interdisciplinar em Ciências Humanas. Publicação no Portal de Periódicos UFSC. As ideias expressadas neste artigo são de responsabilidade de seus autores, não representando, necessariamente, a opinião dos editores ou da universidade.

\section{EDITORES}

Javier Ignacio Vernal e Silmara Cimbalista

HISTÓRICO

Recebido em: 19-05-2019 - Aprovado em: 18-12-2019 - Publicado em: 31-01-2020 